\title{
The Effect of Physiological Cyclic Stretch on the Cell Morphology, Cell Orientation and Protein Expression of Endothelial Cells
}

\author{
V. Barron \\ National University Ireland Galway \\ Claire Brougham \\ Technological University Dublin, claire.brougham@tudublin.ie \\ K. Coghlan \\ National University of Ireland, Galway
}

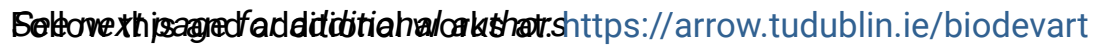

Part of the Biomechanics and Biotransport Commons, and the Other Biomedical Engineering and Bioengineering Commons

\section{Recommended Citation}

Barron, V. et al. (2006) The Effect of Physiological Cyclic Stretch on the Cell Morphology, Cell Orientation and Protein Expression of Endothelial Cells. Journal of Material Sciences: Materials Medicine vol. 18, pp.1973-1981. doi:10.1007/s10856-007-3125-3

This Article is brought to you for free and open access by the Biomedical Devices and Assistive Technology Research Group at ARROW@TU Dublin. It has been accepted for inclusion in Articles by an authorized administrator of ARROW@TU Dublin. For more information, please contact arrow.admin@tudublin.ie, aisling.coyne@tudublin.ie,gerard.connolly@tudublin.ie. Funder: Programme for Research in Third Level Institutions (PRTLI), administered by the Higher Education Authority (HEA), Science Foundation Ireland and the Embark Initiative, operated by the Irish Research Council for Science, Engineering and Technology (IRCSET)

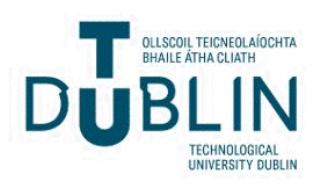


Authors

V. Barron, Claire Brougham, K. Coghlan, C. Stenson-Cox, D. O'Mahoney, and P.E. McHugh

This article is available at ARROW@TU Dublin: https://arrow.tudublin.ie/biodevart/8 
The Effect of Physiological Cyclic Stretch on the Cell Morphology, Cell Orientation and Protein Expression of Endothelial Cells

V. Barron ${ }^{1}$, C. Brougham ${ }^{1,2}$, K. Coghlan ${ }^{1,2}$, C. Stenson-Cox ${ }^{1}$, D. O’Mahoney ${ }^{1}$, P.E.

$$
\text { McHugh }^{1,2}
$$

${ }^{1}$ National Centre for Biomedical Engineering Science, National University of Ireland, Galway, Galway, Ireland

${ }^{2}$ Department of Biomedical and Mechanical Engineering, National University of Ireland, Galway, Galway, Ireland

\section{Corresponding Author}

Dr Valerie Barron

National Centre for Biomedical Engineering Science

National University of Ireland, Galway

Galway

Ireland

Tel: +35391492805

Fax: +35391750596

E-mail address: valerie.barron@ nuigalway.ie

Keywords: Mechano-transduction rig, physiological cyclic stretch, endothelial cells, mathematical model, cell morphology, protein expression

\section{Word Count:}




\section{Nomenclature}

$\delta \quad$ Engineering strain

$\theta \quad$ Angle of cells orientation to applied stretch

$v \quad$ Poisson's ratio

$\varepsilon \quad$ Green's strain

$\gamma \quad$ Shear strain

$\mathrm{N} \quad$ Number of data point (50)

F Cumulative distribution (CDF) for Normal distribution

S CDF for experimental distribution

$D_{N} \quad$ Difference in CDF's

$\mathrm{T}_{\mathrm{KS}} \quad$ Kolmogorov - Smirnov test statistic

\section{Subscripts}

$\mathrm{x}, \mathrm{y} \quad$ Cartesian co-ordinates

aa Axial direction along cell 


\begin{abstract}
In vivo, endothelial cells of the coronary artery are constantly exposed to pulsatile shear and tensile stresses. The main aim of this study was to design and build a mechano-transduction rig, which reproduced homogenous strain profiles of the tensile strain experienced in vivo, and to investigate the effect of this cyclic tensile strain on the cell morphology, cell orientation and protein expression of endothelial cells. The biological response of human umbilical vein endothelial cells to a uni-axial cyclic stretch, in this newly developed bioreactor, was examined experimentally and compared to a mathematical model. In the model, it was revealed that endothelial cells had a strain threshold value of $2.5 \%$ when exposed to a $10 \%$ cyclic strain at $1 \mathrm{~Hz}$ for 3 hours. Following phalloidin staining and confocal imaging to detect actin distribution, it was found that the cells elongated and oriented at $65^{\circ}$ to the direction of applied stress. A decrease in VCAM-1 and an increase in ICAM-1 protein levels were observed in response to the cyclic strain compared to those cells cultured under static conditions. These levels of protein are comparable with in vivo levels and thus validate the bioreactor as replicating the physiological environment.
\end{abstract}




\section{Introduction}

Atherosclerotic lesion development, a hallmark of atherosclerosis, does not occur randomly within the vasculature but rather prevails at certain sites, associated with high stress and high stretch (Sumpio, 1991), such as discontinuities in the arterial trees, the branches of the coronary arteries and the carotid bifurcation. It has been hypothesized that certain mechanical factors such as pressure induced wall stress and blood flow disturbances are contributing factors to the localization of atherosclerotic lesions (Nerem, 1992, Thubrikar and Robicsek, 1995, Zhao, et al., 2002).

The endothelial cell (EC) layer that lines the entire vascular system is a metabolically active monolayer that regulates a variety of biological responses and physiological functions (Topper and Gimbrone, 1999). Alterations in EC gene and protein expression underpin a number of features characteristic of cardiovascular disease including monocyte-endothelial interactions. Due to the constant pulsatile blood flow through the circulatory system, EC are constantly exposed to a shear and tensile stress (Stenson-Cox, et al., 2004). Various in vitro investigations have examined these mechanical stresses both independently and in combination. (Chen, et al., 2001, Davies, 1995, Davies, 1997, Lehoux and Tedgui, 2003, Resnick, et al., 2003, Wang, et al., 1995 Ando and Kamiya, 1996, Ando, et al., 1994, Ando, et al., 1995, Chen, et al., 2001, Davies, 1995, Davies, 1997, Davies and Tripathi, 1993, Flaherty, et al., 1972, Florian, et al 2003, Gimbrone, et al., 1997, Gimbrone, et al., 2000, Kano, et al., 2000, Korenaga, et al., 1997, Mohan, et al., 2003, Nerem, 1992, Nerem and Girard, 1990, Qui, et al 2000, Sumpio, 1991, Topper, et al., 1996, Topper and Gimbrone, 1999, Tsao, et al., 1996, Tsuboi, et al., 1995, Wang, et al., 2000, Wasserman, et al., 2002). However, these studies have been carried out on 
endothelial cells from a variety of sources using a wide range of physiological parameters, including various physiological testers, frequencies and strain rates. Due to inconsistent testing materials and methods, it is difficult to compare and extrapolate the results obtained from one experimental study to another.

Although the biological response of endothelial cells subjected to fluid flow has been extensively studied, the biological response of endothelial cells on deformable substrates subjected to cyclic strain still requires further characterisation. Many of the studies seed cells on circular substrates to which a vacuum is applied (Cheng, et al., 1996, Riser, et al., 1999, Yun, et al., 1999). A shortfall of such studies means that the cells are exposed to a heterogeneous strain field with minimum strain at the centre of the membrane and a maximum strain at the periphery. Cell morphology and cell orientation observed on these circular substrates tend to be more heterogeneous due to the nature of the strain applied (Chen, et al., 2001, Riser, et al., 1999, Yun, et al., 1999).

This study aims to address some of these issues by employing finite elelment analysis (FEA), biomechanical engineering principles and biological techniques to design, build and validate a physiological simulator for pulsatile stretch investigations. Using FEA, the strain profile of the circular substrates outlined above was evaluated and compared to rectangular strips. Using these analyses, a physiological simulator capable of exposing rectangular substrates to in vivo levels of pulsatile strain was developed. Mathematical modelling was employed to predict the effect of the cyclic stretch on the cellular response. To validate the system, cell morphology and cell orientation was examined and compared to the mathematical 
model. An added dimension to this research was the use of molecular biology techniques to validate the system by comparing the cell response on the simulator to the cellular response experienced in vivo.

\section{Materials \& Methods}

\subsection{Finite element analysis}

Finite element analysis was used to investigate the actual strain profiles on circular deformable substrates used in previous studies. FEA was then used to design a substrate which would give a uniform strain profile when uni-axial strain was applied to it. This way it can be ensured that the substrate shape chosen has a homogeneous strain field.

\subsection{Design and development of mechano-transduction rig}

The basic working principle of the mechano-transduction rig developed to evaluate endothelial cell response to uni-axial cyclic stretching is shown in Figure 2 and consists of the cell-seeded silicone substrate, clamped at both ends, is stretched by moving one of the clamps, relative to the other fixed clamp, along the long axis of the silicone membrane. The rig itself was made from PMMA, a biocompatible transparent material that allowed visualization of the test. The fixed grip of the rig was designed so that it was self-tightening upon loading and would not loosen during testing. The rig was easily mounted into the environmental chamber of an Instron 8874 tensile testing machine, where cyclic conditions were applied to the cell seeded silicone system in a precisely controlled, recordable and repeatable manner. The environmental chamber provided the required physiological conditions during the test. 
During the test the cell-seeded silicone substrates were subjected to a $10 \%$ cyclic strain at a frequency of $1 \mathrm{~Hz}$ for 3 hours in phosphate buffered solution at $37^{\circ} \mathrm{C}$ in the environmental chamber.

\subsection{Cell culture and treatment}

Studies were performed using human umbilical vein endothelial cell (HUVEC) obtained from Cambrex, UK. Cells were maintained in HUVEC EBM-2 Bullet kit media (Cambrex, UK). Cells were propagated at $37^{\circ} \mathrm{C}$, in a humidified incubator with a 5\% $\mathrm{CO}_{2}$ air atmosphere and were used at passages 2-5. The silicone strips $12.5 \mathrm{~mm}$ X $50 \mathrm{~mm}$ X $1.0 \mathrm{~mm}$ were sterilized using an ultra violet source for 1

hour. The cells were seeded onto the strips at a density of $40,000 / \mathrm{cm}^{2}$ under sterile conditions and were subjected to either a $10 \%$ cyclic strain at a frequency of $1 \mathrm{~Hz}$ for 3 hours or to a $0 \%$ strain in the mechano-transduction rig $\left(37^{\circ} \mathrm{C}\right.$, humidified incubator, $5 \% \mathrm{CO}_{2}$ ). To examine the effect of physiological stretch alone on cell behaviour, cells were grown to subconfluency to avoid cell - cell interactions. The sampling process for the statistical analysis involved selecting regions containing 50 cells with few cell-cell interactions (Neidlinger-Wilke, et al., 2001).

The substrate upon which the cells are seeded plays a very important role when applying the cyclic stretch. The chosen substrate has to be elastic when subjected to cyclic stretch, be biocompatible, non-toxic to cells and have suitable surface properties for efficient cell attachment. The material used in this study was a commercially available silicone elastomer (Good Fellow, U.K.) with a Youngs modulus of $1.8 \mathrm{MPa}$, a tensile strength of $6.5 \mathrm{MPa}$ and a percentage elongation at 
break of $300 \%$. Prior to cell seeding, silicone substrates were plasma treated in air for 10 minutes using 150 Watts in a Europlasma Junior Plasma Treatment chamber.

\subsection{Statistical Methods}

In a previous study, (Wang, et al., 1995) states that the cell axial strain $\left(\varepsilon_{a a}\right)$, varies with the angle $(\theta)$ to the applied stretch (Figure 3a) and Poisson's ratio $(v)$ as:

$$
\varepsilon_{a a}=\varepsilon_{x x} \cos ^{2}(\theta)+\varepsilon_{y y} \sin ^{2}(\theta)+\frac{\gamma_{x y}}{2} \sin (2 \theta)
$$

For the experiments of (Wang, et al., 1995) and for the experiments reported here, $x$ is the substrate stretch direction and $y$ is the transverse substrate contraction direction. For this choice of axes and loading, the shear strain $\gamma_{x y}$ is zero. Also $\varepsilon_{x x}$ and $\varepsilon_{y y}$ are the Green's (large) strain components given by:

$$
\begin{aligned}
& \varepsilon_{x x}=\delta_{x}+\delta_{x}^{2} / 2 \\
& \varepsilon_{y y}=\delta_{y}+\delta_{y}^{2} / 2
\end{aligned}
$$

where $\delta$ is the engineering strain. Also, from the definition of Poisson's ratio:

$$
\delta_{y}=-v \delta_{x}
$$

Using the experimental values of $\delta_{x}$ equal to 0.1 , a Poisson's ratio of 0.35 and a zero shear strain, the distribution of axial strain is determined from equation (1) for a range of cell orientations and shown in Figure $3 b$. From this plot, it can be seen that a minimum value of axial strain occurs at $63^{\circ}$, where the cells experience a net strain of zero along their axial direction.

\subsection{SEM and Immunocytochemistry studies}

Cell morphology and orientation was examined using scanning electron microscopy (SEM) and confocal laser scanning microscopy (Zeiss LSM 510) 
(CSLM). Immediately after mechanical stimulation or static conditions endothelial cells were fixed and stained for analysis described below. For SEM examination the endothelial cells were fixed with gluteraldehyde and dehydrated with increasing concentrations of ethanol up to $100 \%$ and dried using critical point drying. The cells were then coated with a thin layer of gold to permit conductivity of the sample for SEM examination. Fluorescent conjugates of phalloidin (Molecular Probes, UK) were used to label the actin filaments for examination of cell morphology and cell orientation. Propidium iodide (Molecular Probes, UK), which binds to cellular DNA and RNA was used to visualise the nucleus, while FITC conjugated mouse antihuman ICAM-1 and VCAM-1 monoclonal antibodies (TCS Cellworks, UK) were used to stain for protein expression of the aforementioned adhesion molecules. Additionally, analysis of the expression of ICAM-1 and VCAM-1 was conducted using Image Pro® Plus analysis software (Media Cybernetics, UK) where the protein expression was visually quantified by measuring the area of green fluorescence present, representing each adhesion molecule, compared to the area of the nucleus of the cell.

\section{Results}

\subsection{Finite Element Analysis}

In this study it has been shown through finite element analysis that the actual strain profile on circular deformable substrates used in previous studies (Cheng, et al., 1996, Riser, et al., 1999, Yun, et al., 1999) varies significantly from the average

profile. Radially the percentage difference ranges from $-28 \%$ to $31 \%$ and circumferentially from $-42 \%$ to $+62 \%$ shown in Figure 1 . 
The substrate shape, which would ensure a homogenous strain profile, is a rectangular shaped substrate, which has been implemented into this rig design. $<<<$ Refer to Karen's rectangular substrate strain profile results $>>>$

\subsection{Cell Morphology}

As mentioned previously the cell orientation and cell morphology was examined using SEM and CLSM. The direction of stretch is indicated by the arrow to the right of the images (Figure 4-6). The images obtained using SEM reveal the general outline of cell orientation and cell morphology (Figure 4), while the images obtained from the CLSM revealed more details in terms of the orientation and morphology of the nucleus (Figure 5) and the actin filaments of the cell (Figure 6).

From the SEM images in Figure 4a it can be seen that the cells grown in static culture were randomly oriented and had cobblestone morphology. However, the cells subjected to cyclic stretch (Figure 4b) were seen to elongate and realign obliquely to the direction of stretch. This is further evidenced in Figure 5 in propidium iodide stained CLSM images, where it can be seen that the nuclei of the cells grown in static culture were randomly oriented (Figure 5a), while Figure 5b reveals that the nuclei of the stretched endothelial cells begin to elongate and realign at an angle to the direction of stretch.

This is also highlighted in the phalloidin stain for the actin filaments of the cytoskeleton. The actin filaments of the endothelial cells were also seen to respond to the cyclic stretch. Compared to the randomly oriented actin filaments in the cells grown in static culture (Figure 6a), the actin filaments of the stretched cells were 
remodelled into stress fibres which oriented obliquely to the direction of stretch, as shown in Figure 6b.

\subsection{Cell Orientation}

To study the effect of cyclic stretch on cell reorientation specifically, the endothelial cell orientation distributions were obtained using statistical analysis, and are shown in Figure $7 \mathrm{a}$ and $7 \mathrm{~b}$. This was conducted by manually tracing the perimeter of each cell and drawing the major axis of the acquired shape. The orientation angle was found by measuring the angle between the major axis and the baseline, represented by the stretching direction. The acute angle between the perpendicular baseline and the major axis of the cell was recorded and all results were between $0^{\circ}$ and $90^{\circ}$. An angle of $0^{\circ}$ was indicative of cell aligned perfectly parallel to the stretching direction, while an angle of $90^{\circ}$ was indicative of the cell aligned perfectly perpendicular to the stretching direction. From these cell orientation measurements, cell frequency distributions were calculated and are shown in Figure 7. As shown in Figure 7a, the orientation of the mechanically conditioned endothelial cells was in the range $62.5^{\circ}$ to $67.5^{\circ}$ with a peak at $65^{\circ}$, while a random orientation was observed for cells grown in static culture (Figure 7b).

It should be noted also that $80 \%$ of the cells measured fall between an orientation of $50^{\circ}$ and $80^{\circ}$ (Figure 7a), this gives a threshold strain of 0.025 as can be seen from the solid line in figure $3 b$ for the axial strain analysis. Further, $96 \%$ of the cells measured fall within $50^{\circ}$ to $90^{\circ}$, this corresponds to a standard deviation for the axial strain of 0.01 as can be seen from the broken line in figure $3 \mathrm{~b}$. 


\subsection{Statistical Analysis}

The cell orientation can also be expressed by equation (4) which is derived by setting the shear strain term in equation (1) to zero and re-arranging to give:

$$
\theta=\cos ^{-1}\left(\sqrt{\frac{2\left(\varepsilon_{a a} / \delta_{x}\right)+\left(2 v-v^{2}\right) \delta_{x}}{2(1+v)+\left(1-v^{2}\right) \delta_{x}}}\right)
$$

By assuming that $\theta$ follows a normal distribution, with a mean axial strain of $2.5 \%$ and a standard deviation of $1 \%$ a sample of $\varepsilon_{\mathrm{aa}}$ was generated. This was achieved by using fifty random numbers on $[0,1]$ and inverting cumulative distribution function. These values were then replaced in equation (4) and a distribution of cell orientation obtained as seen in figure $7 \mathrm{c}$.

To determine if the measured distribution of the cells follows a normal distribution, a Kolmogorov - Smirnov test is performed. In this case $D_{N}$ is defined as:

$$
D_{N}=\max \left|S_{N}(\theta)-F(\theta)\right|
$$

Here, $S_{N}$ is the cumulative distribution function of the measured $N$ data points $(N=50)$ and $F$ is the cumulative distribution function for the normal distribution. In this study, the maximum difference in the cumulative distribution function $\left(D_{N}\right)$ for the measured angular position and the theoretical one is 0.27 (Figure 7d). As both distributions have 50 samples a test statistic D* was obtained for the Kolmogorov - Smirnov two sample test of:

$$
D^{*}=N_{1} N_{2} D_{N}=50.50(0.27)=675
$$

Using Neave, 1979, this is not significant at the $\alpha 2=5 \%$ level, as the critical region is $\mathrm{D}^{*}>700$. The $\mathrm{D}^{*}$ obtained corresponds to an $\alpha 2$ value of approximately $7.5 \%$. The difference between the values predicted and the values measured may be due to operator dependence and instrument control used to measure cell orientation. 


\subsection{Protein Expression}

ICAM-1 protein levels are increased in endothelial cells that were cyclically stretched compared to the control samples grown in static culture (Figure 8). In contrast to the CLSM image representing ICAM-1 expression a decrease in VCAM-1 protein expression was observed in cyclically stretched cells as compared to those cultured under static conditions (Figure 9).

Using Image Pro analysis software to examine the amount of green fluorescence, an increase of $11.5 \%$ in ICAM-1 was determined for the cyclically stretched cells, while a $13 \%$ decrease in the expression of VCAM-1 was observed for the mechanically conditioned cells compared to control cells in static culture. Using this method it is not possible to conduct a statistical analysis, but the resolution of the camera for image analysis and the sensitivity of the image analysis software is accurate to within $0.5 \%$ error, which confirms the trend observed.

\section{Discussion}

In this study, finite element analysis was used to validate a homogenous strain profile for a mechano-transduction rig, which was designed and built, capable of mimicking the physiological strain profiles in vivo. This rig was used to expose endothelial cells, which were successfully cultured on modified silicone substrates, to cyclic stretching similar to that found in the native artery. Herein, cell orientation was predicted to be in the region of $63^{\circ}$ using axial strain analysis, in the range $60.5^{\circ}$ to $64.5^{\circ}$ using the computer simulation and experimentally was found to be $65^{\circ}$ from the vertical, thus echoing the predictions of McGarry, et al., 2004 for endothelial cells. 
To develop a deeper understanding of the role of mechanical stimulation on cellular response, various computational models and experimental studies have been conducted to explain the role of mechanical stimulation on cellular response (Moretti, et al., 2004, McGarry, et al., 2004, Neidlinger-Wilke, et al., 2001, Wang, et al., 1995). Wang, et al. 1995 developed a model which revealed that at $12 \%$ strain, melanocyte cell orientations tended toward a normal distribution with the greatest number of cells orienting at $60^{\circ}$ to the direction of stretch, while at lower strain levels of $4 \%$ and $8 \%$ the cells were found to exist in a more random distribution.

Wang, et al., 1995 suggested that this cell orientation response could be explained by the cells attempting to reduce their axial deformation to a level below the axial substrate strain threshold. For melanocytes a mean strain threshold was determined to be $3.5 \%$ (Wang, et al., 1995). In a separate study, Neidlinger-Wilke, et al., 2001 used a similar model and found a strain threshold for cell orientation of $6.4 \%$ for osteoblasts and $4.2 \%$ for fibroblasts. In this study it was revealed that endothelial cells had a strain threshold value of $2.5 \%$ when exposed to a $10 \%$ cyclic strain at $1 \mathrm{~Hz}$ for 3 hours, thereby providing a further insight into the cellular response of endothelial cells to physiological levels of cyclic strain.

Previous studies suggested that the reorientation response of the cell may have an effect in inducing gene expression (Dancu, et al., 2004) and in directing cellular mRNA levels and protein synthesis (Carver, et al., 1991, Leung, et al., 1976, Wang, et al., 1995). Application of shear stress to cells in vitro has been shown to regulate the expression of adhesion molecules including vascular adhesion molecule-1 (VCAM-1) 
and intracellular adhesion molecule-1 (ICAM-1) (Chen, et al., 2001, Lelkes, et al., 1998, Sprague, 1999, Topper and Gimbrone, 1999, Yoshisue, et al., 2002). In contrast to shear stress, the effect of cyclic tensile stretch on the expression of adhesion molecules in EC is less defined. Evidence from other studies suggests a selective sensitivity of EC adhesion molecules to cyclic radial strain applied in vitro (Cheng, et al., 1996, Yun, et al., 1999). While there was no change in levels of VCAM-1 expression in EC subjected to the heterogenous radial strain profiles discussed earlier, there was an induction in ICAM-1 expression for these cells compared to cells under static conditions (Yun, et al., 1999). The application of a homogeneous strain profile to the cells, the use of scanning electron microscopy, molecular biology staining techniques and confocal laser microscopy to examine the cell morphology and cell orientation analysis is an exciting dimension to this study. Qualitatively, it can be observed that there is an increase in ICAM-1 and a decrease in VCAM-1 observed for the cells exposed to $10 \%$ strain at $1 \mathrm{~Hz}$ for 3 hours compared to controls in static culture.

Using the engineering approach of combining finite element analysis, mechanical design and biological evaluation, this data gives a more representative view of the effect of in vivo mechanical strain on the biological response of cells compared to those observed in radial strain test systems (Cheng, et al., 1996, Riser, et al., 1999, Stenson-Cox, 2004, Yun, et al., 1999). In summary, these results provide a fundamental insight to the effect of physiological levels of strain on the biological response of endothelial cells and have important implications for hypertension and atherosclerosis studies. 


\section{Acknowledgements}

This work is funded by the Higher Education Authority PRTLI research funding programme, Science Foundation Ireland and the Embark Initiative, operated by the Irish Research Council for Science, Engineering and Technology (IRCSET). The authors would like to acknowledge the help and support of Dr Bruce P. Murphy, Dr Margaret O’Brien, Ms Emily McLucas, Dr. Michael Ball, Dr Eadaoin Timmins and Mr William Brennan, National Centre for Biomedical Engineering Science, National University of Ireland, Galway, Ireland. 


\section{List of Figures}

Figure 1 Graph showing difference in actual radial and circumferential strain to average radial and circumferential strain in the deformable circular substrate under vacuum model.

Figure 2 Schematic diagram of purpose-built mechano-transduction rig.

Figure 3 (a) Schematic diagram illustrating the effect of applied stretch (b) The variation of axial strain as a function of cell orientation .

Figure 4 SEM image of (a) control cells in static culture (b) cyclically stretched cells. Figure 5 CLSM image of phalloidin stained (a) control cells in static culture (b) cyclically stretched cells.

Figure 6 CLSM image of phalloidin stained (a) control cells in static culture (b) cyclically stretched cells.

Figure 7 Experimental observation of cell orientation for (a) cells with $0 \%$ strain (b) cells cyclically stretched at $10 \%$ strain at $1 \mathrm{~Hz}$ for 3 hours (c) Predicted cell frequency distribution (d) Difference between CDF for experimental and predicted data Figure 8 Green Fluorescence Expression of ICAM-1 for (a) cells grown in static culture (b) cyclically stretched cells. Note: Red fluorescence shows actin binding. Figure 9 Green Fluorescence Expression of VCAM-1 for (a) cells grown in static culture (b) cyclically stretched cells. Note: Red fluorescence shows actin binding. 
Figure 1

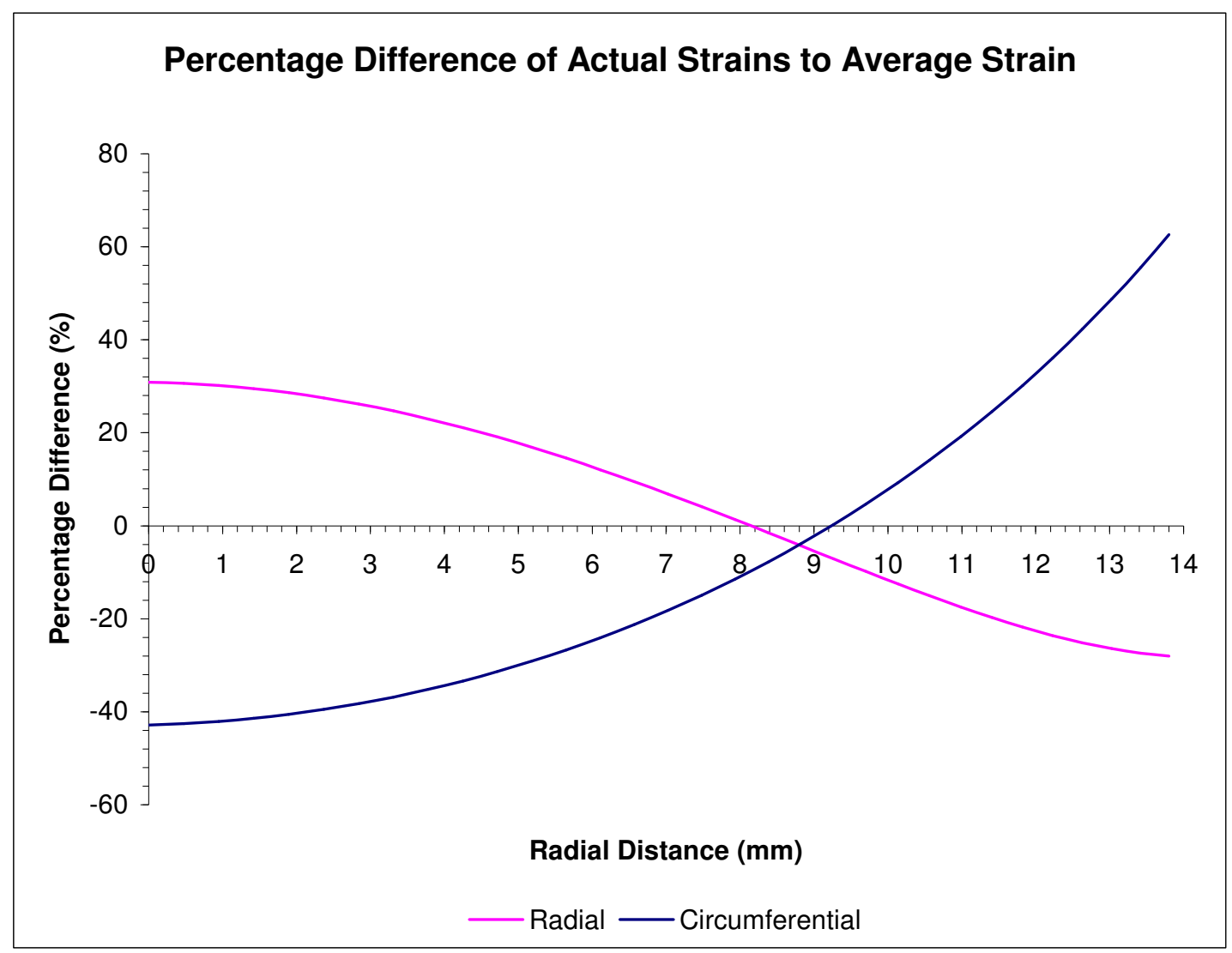


Figure 2

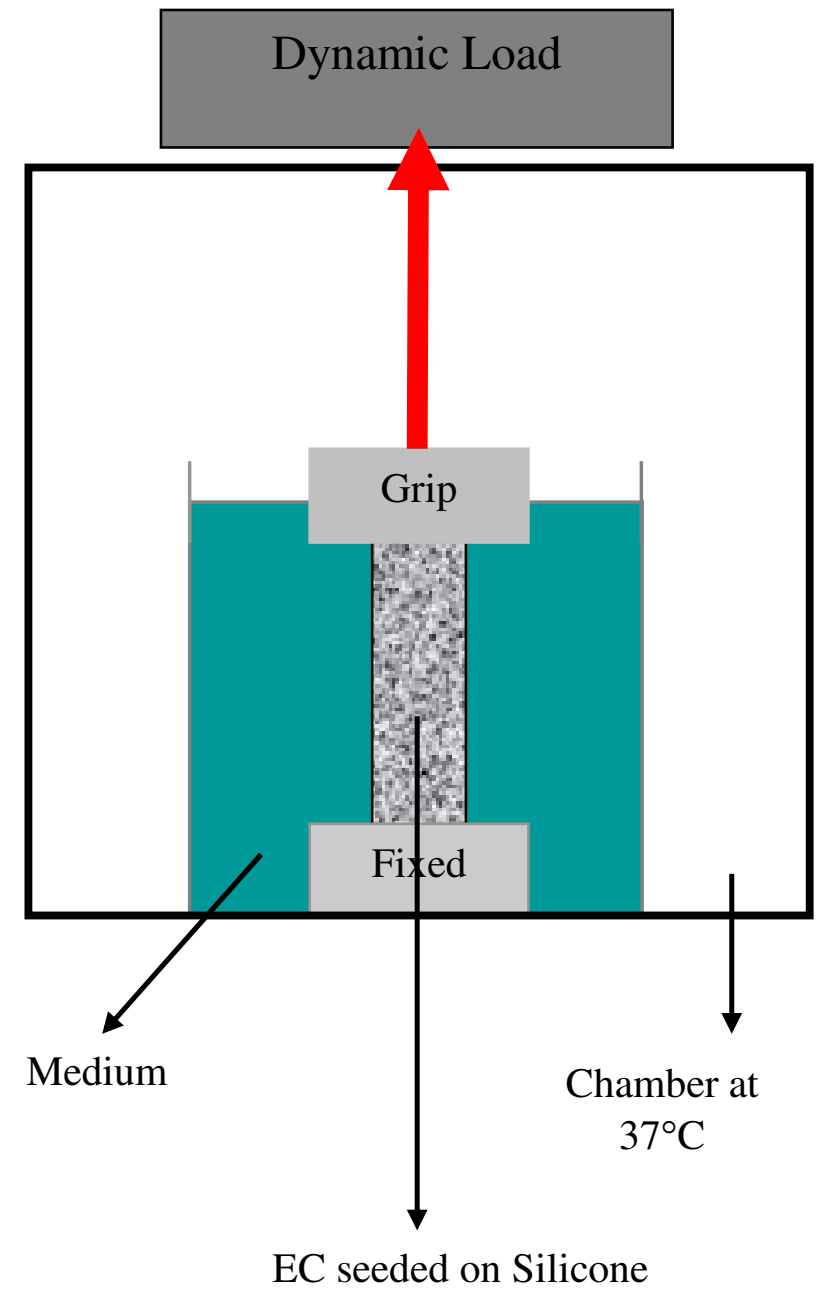


Figure $3 \mathrm{a}$ and $\mathrm{b}$
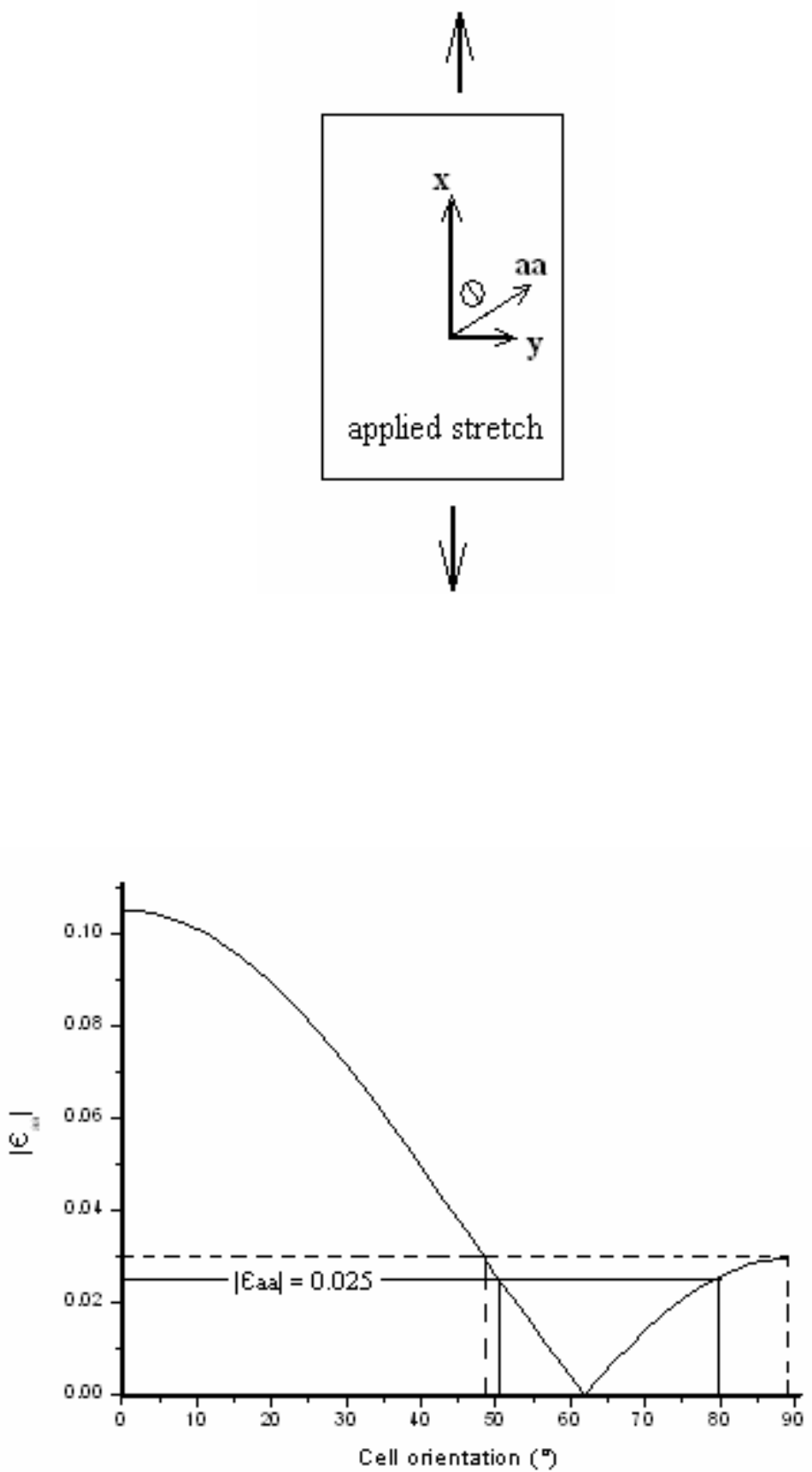
Figure $4 \mathrm{a}$ and $\mathrm{b}$
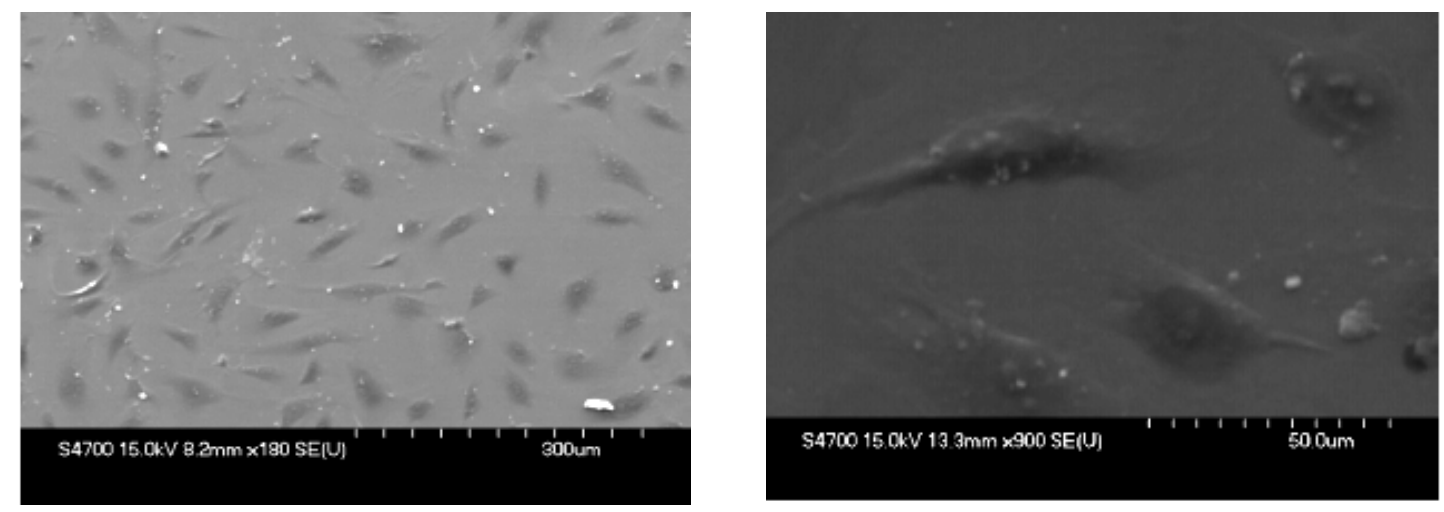
Figure $5 \mathrm{a}$ and $\mathrm{b}$
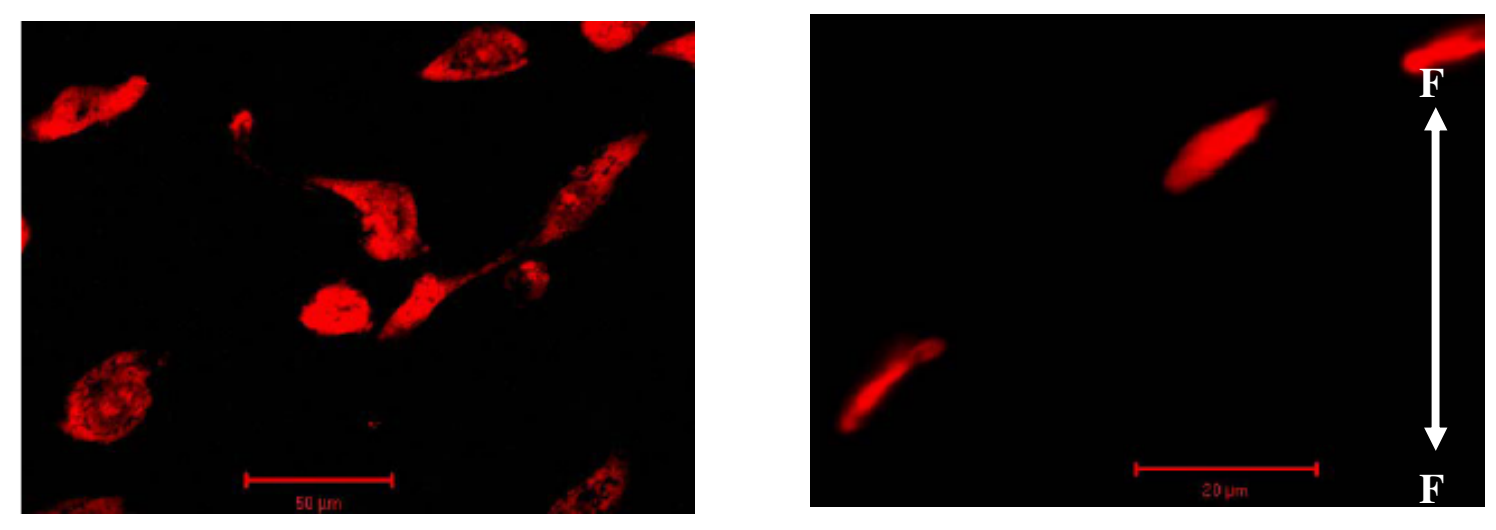
Figure $6 \mathrm{a}$ and $\mathrm{b}$
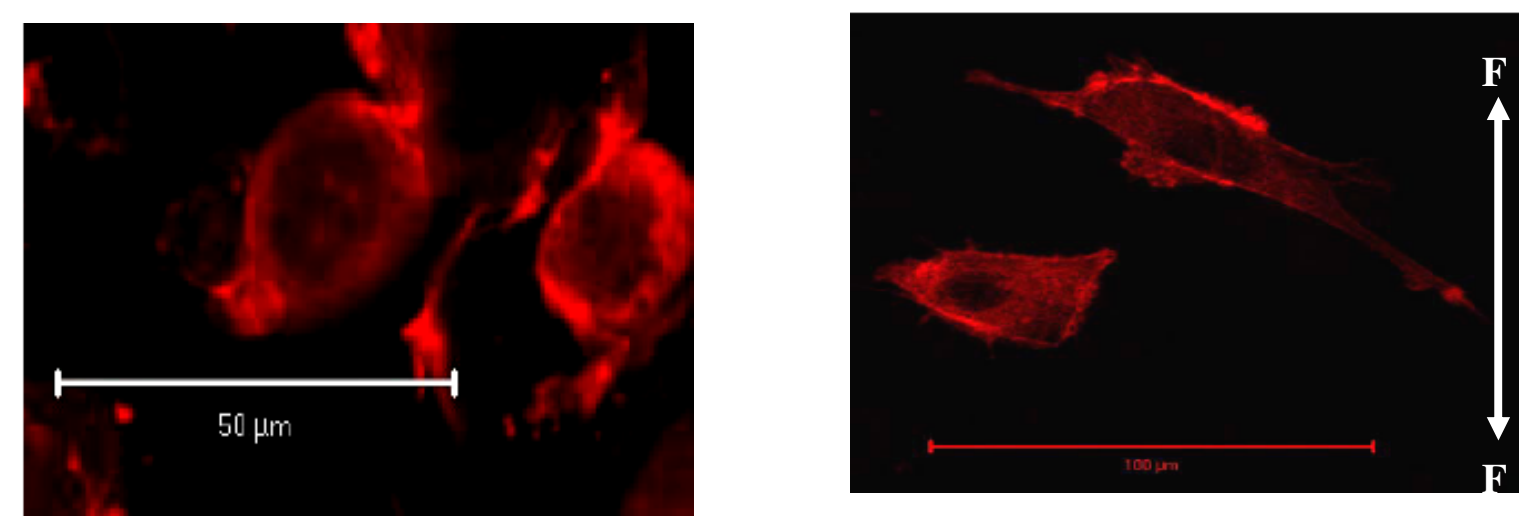
Figure 7 a, b, c, and d
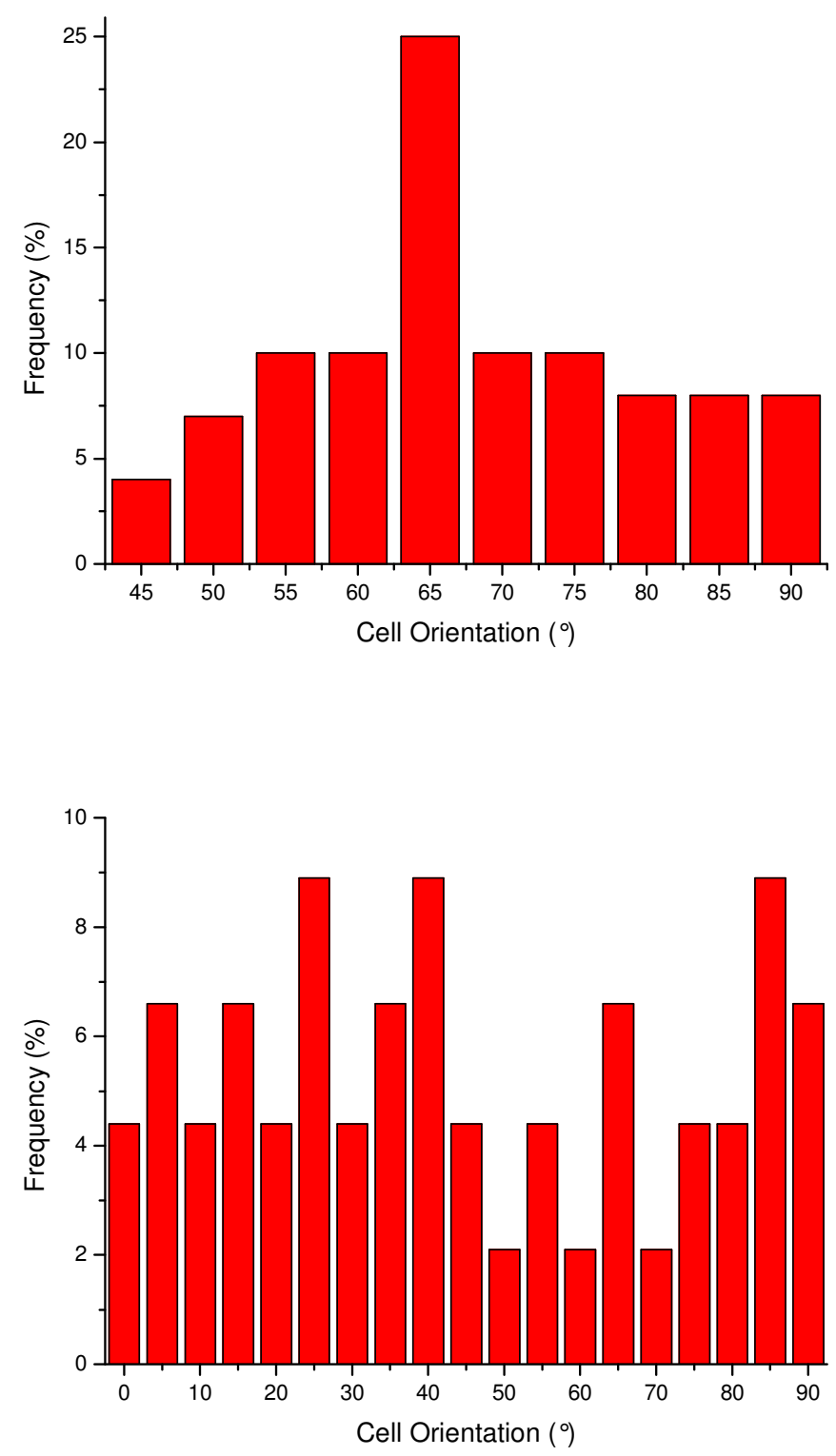

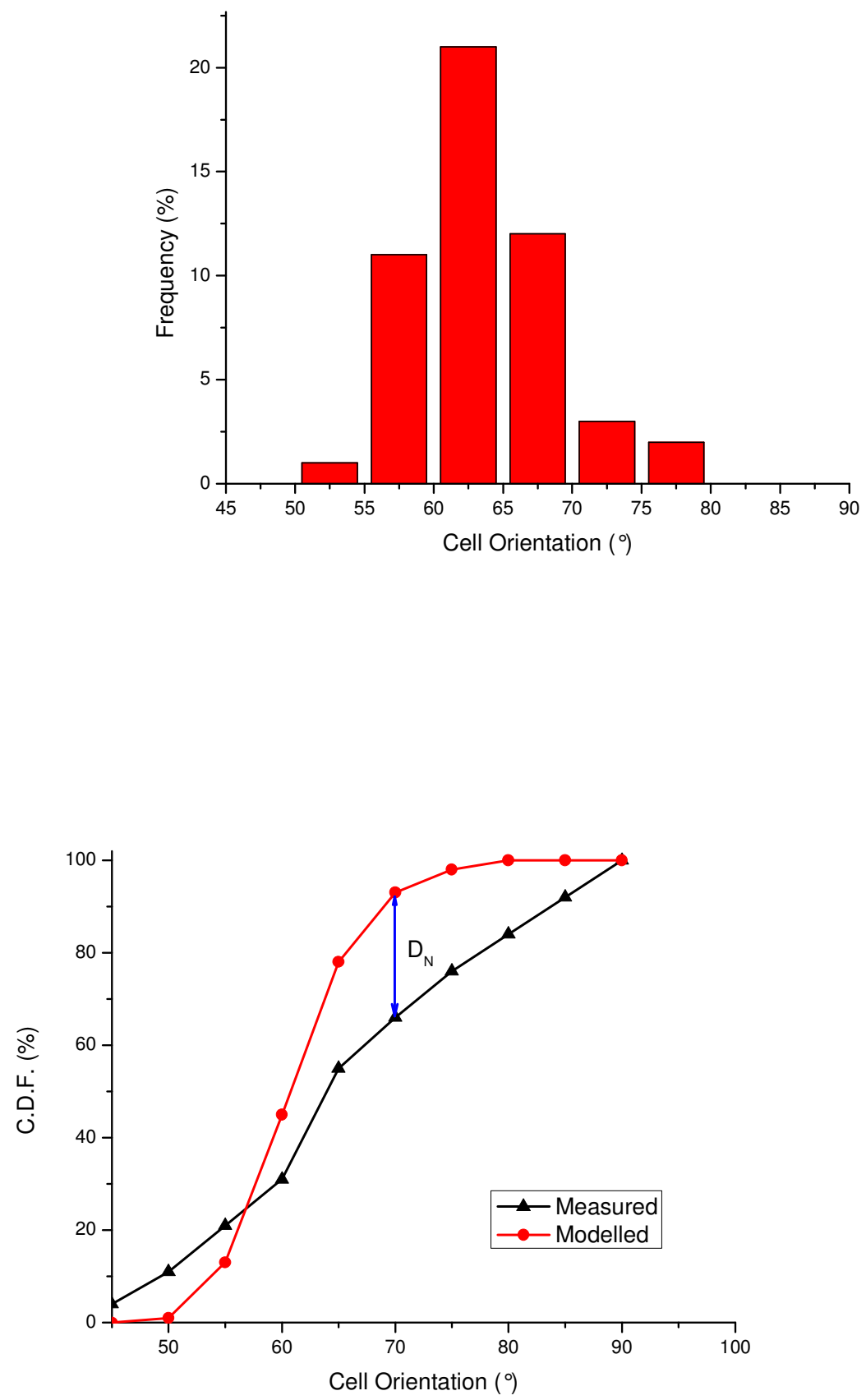
Figure $8 a$ and $b$
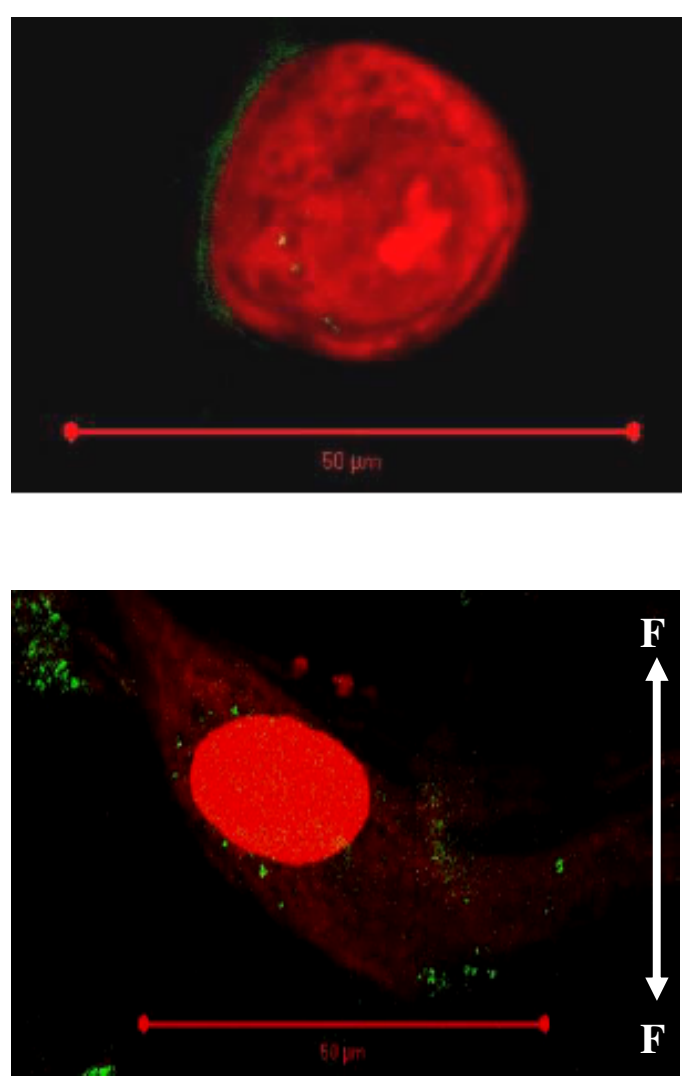
Figure $9 \mathrm{a}$ and $\mathrm{b}$
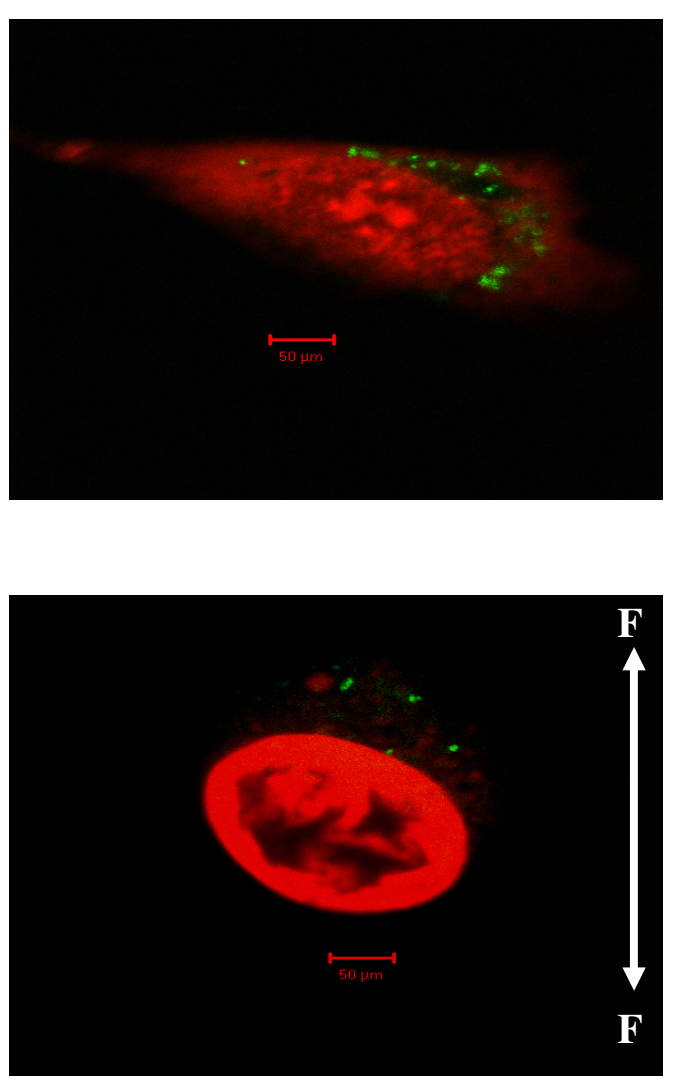


\section{References}

1 Sumpio B. E., 1991. Hemodynamic forces and vascular cell biology. RG Landes Publishers, Austin, TX, USA.

2 Nerem, R. M., 1992. Vascular fluid mechanics, the arterial wall, and atherosclerosis. Journal of Biomechanical Engineering 114, 274-282.

3 Thubrikar, M. J., Robicsek F., 1995. Pressure-induced arterial wall stress and atherosclerosis. The Annals of Thoracic Surgery 59, 1594-1603.

4 Zhao, S. Z., Ariff, B., Long, Q., Hughes, A. D., Thom, S. A., Stanton, A. V., $\mathrm{Xu}, \mathrm{X}$. Y., 2002. Inter-individual variations in wall shear stress and mechanical stress distributions at the carotid artery bifurcation of healthy humans. Journal of Biomechanics 35, 1367-1377.

5 Topper, J. N,. Gimbrone Jr., M. A., 1999. Blood flow and vascular gene expression: fluid shear stress as a modulator of endothelial phenotype. Molecular Medicine Today 5, 40-46.

6 Stenson-Cox, C., Barron, V., Murphy, B. P., McHugh, P. E., Smith, T., 2004. Profiling the Shear Stress of Atherosclerosis; A Genomic Review. Current Genomics 5, 287-297.

7 Chen, B. P., Li, Y. S., Zhao, Y., Chen, K. D., Li, S., Lao, J., Yuan, S., Shyy J. Y., Chien, S., 2001. DNA microarray analysis of gene expression in endothelial cells in response to 24-h shear stress. Physiological Genomics 7, 55-63.

8 Davies, P. F., 1995. Flow-mediated endothelial mechanotransduction. Physiological Reviews 75, 519-560.

9 Davies, P. F., 1997. Mechanisms involved in endothelial responses to hemodynamic forces. Atherosclerosis 131, S15-17.

10 Lehoux, S. Tedgui, A., 2003. Cellular mechanics and gene expression in blood vessels. Journal of Biomechanics 36, 631-643.

11 Resnick, N., Yahav, H., Shay-Salit, A., Shushy, M., Schubert, S., Zilberman L. C., Wofovitz, E., 2003. Fluid shear stress and the vascular endothelium: for better and for worse. Progress in Biophysics and Molecular Biology 81, 177199.

12 Wang, H., Ip, W., Boissy, R., Grood, E. S., 1995. Cell orientation response to cyclically deformed substrates: experimental validation of a cell model. Journal of Biomechanics 28, 1543-1552.

13 Ando, J., Kamiya, A., 1996. Flow-dependent regulation of gene expression in vascular endothelial cells. Japanese Heart Journal. 37, 19-32. 
14 Ando, J., Tsuboi, H., Korenaga, R., Takada, Y., Toyama-Sorimachi, N., Miyasaka M., Kamiya, A., 1994. Shear stress inhibits adhesion of cultured mouse endothelial cells to lymphocytes by downregulating VCAM-1 expression. American Journal of Physiology 267, C679-687.

15 Ando, J., Tsuboi, H., Korenaga, R., Takada, Y., Toyama-Sorimachi, N., Miyasaka M., Kamiya, A., 1995. Down-regulation of vascular adhesion molecule-1 by fluid shear stress in cultured mouse endothelial cells. Annals of the New York Academy of Sciences 748, 148-156

16 Davies, P. F. Tripathi, S. C., 1993. Mechanical stress mechanisms and the cell. An endothelial paradigm. Circulation Research 72, 239-245.

17 Flaherty, J. T., Pierce, J. E., Ferrans, V. J., Patel, D. J., Tucker W. K., Fry, D. L., 1972. Endothelial nuclear patterns in the canine arterial tree with particular reference to hemodynamic events. Circulation Research 30, 23-33.

18 Gimbrone Jr., M. A., Resnick, N., Nagel, T., Khachigian, L. M., Collins T., J. Topper, N., 1997. Hemodynamics, endothelial gene expression, and atherogenesis. Annals of the New York Academy of Sciences 811, 1-10.

19 Gimbrone Jr., M. A., Topper, J. N., Nagel, T., Anderson, K. R., GarciaCardena, G., 2000. Endothelial dysfunction, hemodynamic forces, and atherogenesis. Annals of the New York Academy of Sciences 902, 230-240.

20 Kano, Y., Katoh, K., Fujiwara, K., 2000. Lateral zone of cell-cell adhesion as the major fluid shear stress-related signal transduction site. Circulation Research 86, 425-433.

21 Korenaga, R., Ando, J., Kosaki, K., Isshiki, M., Takada Y., Kamiya, A., 1997. Negative transcriptional regulation of the VCAM-1 gene by fluid shear stress in murine endothelial cells. American Journal of Physiology 273, C1506-1515.

22 Mohan, S., Hamuro, M., Sorescu, G. P., Koyoma, K., Sprague, E. A., Jo, H., Valente, A. J., Prihoda T. J., Natarajan, M., 2003. IkappaBalpha-dependent regulation of low-shear flow-induced NF-kappa B activity: role of nitric oxide. American Journal of Physiology Cell Physiology 284, C1039-1047.

23 Nerem, R. M., Girard, P. R., 1990. Hemodynamic influences on vascular endothelial biology. Toxicologic Pathology 18, 572-582.

24 Topper, J. N., Cai, J., Falb D., Gimbrone Jr., M. A., 1996. Identification of vascular endothelial genes differentially responsive to fluid mechanical stimuli: cyclooxygenase-2, manganese superoxide dismutase, and endothelial cell nitric oxide synthase are selectively up-regulated by steady laminar shear stress. Proceedings of the National Academy of Sciences 93, 10417-10422.

25 Tsao, P. S., Buitrago, R., Chan J. R., Cooke, J. P., 1996. Fluid flow inhibits endothelial adhesiveness. Nitric oxide and transcriptional regulation of VCAM-1. Circulation 94, 1682-1689. 
26 Tsuboi, H., Ando, J., Korenaga, R., Takada Y., Kamiya, A., 1995. Flow stimulates ICAM-1 expression time and shear stress dependently in cultured human endothelial cells. Biochemical and Biophysical Research Communications 206, 988-996.

27 Wang, J. H., Goldschmidt-Clermont P., Yin, F. C., 2000. Contractility affects stress fiber remodeling and reorientation of endothelial cells subjected to cyclic mechanical stretching. Annals of Biomedical Engineering 28, 11651171 .

28 Wasserman, S. M., Mehraban, F., Komuves, L. G., Yang, R. B., Tomlinson, J. E., Zhang, Y., Spriggs, F. Topper, J. N., 2002. Gene expression profile of human endothelial cells exposed to sustained fluid shear stress. Physiological Genomics 12, 13-23.

29 Wang, J. H., Goldschmidt-Clermont, P., Wille J., Yin, F. C., 2001. Specificity of endothelial cell reorientation in response to cyclic mechanical stretching. Journal of Biomechanics 34, 1563-1572.

30 Lelkes, P. I., C. S. Kettlun, J. Wigboldus and G. M. Rubanyi, 1998. Signalling mechanisms involved in endothelial activation by perturbed flow. INABIS Symposium Journal of Vascular Research 35, 14

31 Sprague, E. A., 1999. Pathways mediating low shear stress-induced vascular endothelial gene activation. In Proceedings of the American Society of Mechanical Engineers Bioengineering Conference. Big Sky, Montana, USA

32 Yoshisue, H., Suzuki, K., Kawabata, A., Ohya, T., Zhao, H., Sakurada, K., Taba, Y., Sasaguri, T., Sakai, N., Yamashita, S., Matsuzawa, Y., Nojima, H., 2002. Large scale isolation of non-uniform shear stress-responsive genes from cultured human endothelial cells through the preparation of a subtracted cDNA library. Atherosclerosis 162, 323-334.

33 Cheng, J. J., Wung, B. S., Chao, Y. J., Wang, D. L., 1996. Cyclic strain enhances adhesion of monocytes to endothelial cells by increasing intercellular adhesion molecule-1 expression. Hypertension 28, 386-391.

34 Yun, J. K., Anderson J. M., Ziats, N. P., 1999. Cyclic-strain-induced endothelial cell expression of adhesion molecules and their roles in monocyteendothelial interaction. Journal of Biomedical Materials Research Part A 44, 87-97.

35 Carver, W., Nagpal, M. L., Nachtigal, M., Borg T. K., Terracio, L. 1991. Collagen expression in in mechanically stimulated cardiac fibroblasts. Circulation Research 69, 116-122.

36 Leung, D. Y. M., Glagov, S., Mathews, M.B., 1976. Cyclic stretching stimulates synthesis of matrix components by arterial smooth cells in vitro. Science 191, 475-477. 
37 Neidlinger-Wilke, C., Grood, E. S., Wang, J.-C., Brand R. A., Claes, L., 2001. Cell alignment is induced by cyclic changes in cell length: studies of cells grown in cyclically stretched substrates. Journal of Orthopaedic Research 19, 286-293.

38 Riser, B. L., Ladson-Wofford, S., Sharba, A., Cortes, P., Drake, K., Guerin, C. J., Yee, J., Choi, M. E., Segarini P. R., Narins, R. G., 1999. TGF-beta receptor expression and binding in rat mesangial cells: modulation by glucose and cyclic mechanical strain. Kidney International 56, 428-439.

39 Neave, H. R., 1979. Elementary Statistics Tables. Routledge, New York, pp. 31

40 McGarry, J. P., Murphy B. P., McHugh, P. E., 2004. Computational mechanics modelling of cell-substrate contact during cyclic substrate deformation. Journal of Mechanics and Solids Submitted.

41 Florian, J. A., Kosky, J. R., Ainslie, K., Pang, Z., Dull R. O., Tarbell, J. M.,2003. Heparan sulfate proteoglycan is a mechanosensor on endothelial cells. Circulation Research 93, 36-42.

42 Qui, Y., Tarbell, J.M., Interaction between wall shear stress and circumferential strain affects endothelial cell biochemical production. Journal of Vascular Research 37, 147-57.

43 Dancu M. B., Berardi, D. E., Vanden Heuvel J. P., Tarbell, J. M., 2004. Asynchronous shear stress and circumferential strain reduces endothelial NO synthase and cyclooxygenase- 2 but induces endothelin-1 gene expression in endothelial cells. Arteriosclerosis, Thrombosis, and Vascular Biology 24, 2088-94.

44 Moretti M., Prina-Mello A., Reid, A.J., Barron, V. Prendergast P.J. (2004), Endothelial Cell Alignment on Deforming Silicone Surfaces Journal of Materials Science: Materials in Medicine 15,1159-64 